\title{
BMJ Open Comparing the reporting and conduct quality of exercise and pharmacological randomised controlled trials: a systematic review
}

\author{
Scott C Adams (D) , ${ }^{1,2,3}$ Julia McMillan (D) , ${ }^{4}$ Kirsten Salline (D) , ${ }^{5}$ Jessica Lavery (D) , ${ }^{6}$ \\ Chaya S Moskowitz (i) ,6 Konstantina Matsoukas (D), ${ }^{7}$ Maggie M Z Chen (iD) , \\ Daniel Santa Mina (iD) ,3,8 Jessica M Scott (D) , ${ }^{9,10}$ Lee W Jones (iD) ${ }^{9,10}$
}

To cite: Adams SC, McMillan J, Salline K, et al. Comparing the reporting and conduct quality of exercise and pharmacological randomised controlled trials: a systematic review. BMJ Open 2021;11:e048218. doi:10.1136/ bmjopen-2020-048218

- Prepublication history and additional supplemental material for this paper are available online. To view these files, please visit the journal online. To view these files, please visit the journal online (http://dx.doi. org/10.1136/bmjopen-2020048218).

\section{JMS and LWJ contributed} equally.

Received 19 December 2020 Accepted 15 June 2021

Check for updates

(C) Author(s) (or their employer(s)) 2021. Re-use permitted under CC BY-NC. No commercial re-use. See rights and permissions. Published by BMJ.

For numbered affiliations see end of article.

Correspondence to

Dr Lee W Jones;

jones13@mskcc.org

\section{ABSTRACT}

Objective Evaluate the quality of exercise randomised controlled trial (RCT) reporting and conduct in clinical populations (ie, adults with or at risk of chronic conditions) and compare with matched pharmacological RCTs.

Design Systematic review.

Data sources Embase (Elsevier), PubMed (NLM) and CINAHL (EBSCO).

Study selection RCTs of exercise in clinical populations with matching pharmacological RCTs published in leading clinical, medical and specialist journals with impact factors $\geq 15$.

Review methods Overall RCT quality was evaluated by two independent reviewers using three research reporting guidelines (ie, Consolidated Standards of Reporting Trials (CONSORT; pharmacological RCTs)/CONSORT for non-pharmacological treatments; exercise RCTs), CONSORT-Harms, Template for Intervention Description and Replication) and two risk of bias assessment (research conduct) tools (ie, Cochrane Risk of Bias, Jadad Scale). We compared research reporting and conduct quality within exercise RCTs with matched pharmacological RCTs, and examined factors associated with quality in exercise and pharmacological RCTs, separately.

Findings Forty-eight exercise RCTs (11 658 patients; median sample $n=138$ ) and 48 matched pharmacological RCTs were evaluated (18 501 patients; median sample $\mathrm{n}=160$ ). RCTs were conducted primarily in cardiovascular medicine (43\%) or oncology (31\%). Overall quality score (composite of all research reporting and conduct quality scores; primary endpoint) for exercise RCTs was 58\% (median score 46 of 80; IQR: 39-51) compared with 77\% (53 of 68; IQR: 47-58) in the matched pharmacological RCTs $(p \leq 0.001)$. Individual quality scores for trial reporting and conduct were lower in exercise RCTs compared with matched pharmacological RCTs $(p \leq 0.03)$. Factors associated with higher overall quality scores for exercise RCTs were journal impact factor $(\geq 25)$, sample size $(\geq 152)$ and publication year ( $\geq 2013)$.

Conclusions and relevance Research reporting and conduct quality within exercise RCTs is inferior to matched pharmacological RCTs. Suboptimal RCT reporting and conduct impact the fidelity, interpretation, and reproducibility of exercise trials and, ultimately, implementation of exercise in clinical populations. PROSPERO registration number CRD42018095033.

\section{Strengths and limitations of this study}

- A total of $n=30159$ participants from 96 randomised controlled trials (RCTs) of exercise and pharmacological therapies published in high-impact journals were included.

- We used a combination of five established and one investigator-developed inventories to comprehensively evaluate and compare the quality of research reporting and conduct of exercise and pharmacological RCTs.

- Main limitations of the study include the restriction to journals with impact factors $\geq 15$ and the lack of broadly applicable or unified guidelines to compare across exercise and pharmacological therapy RCTs.

\section{INTRODUCTION}

Reports from epidemiological studies and randomised controlled trials (RCTs) indicate that exercise therapy is safe and well tolerated, and associated with broad health benefits in adults. ${ }^{1}$ Accordingly, exercise is considered standard of care therapy for many clinical populations (ie, adults with or at risk of chronic conditions), with established guidelines from numerous international agencies. ${ }^{2-4}$

Clinical recommendation of exercise for a particular clinical indication is predicated on evidence from RCTs. ${ }^{5}$ Optimal reporting of RCTs evaluating pharmacological and non-pharmacological therapies is facilitated by multiple standardised guidelines (eg, Consolidated Standards of Reporting Trials (CONSORT), ${ }^{6} 7$ Template for Intervention Description and Replication (TIDieR)). ${ }^{8}$ Reports of RCTs are required to conform to at least one of these guidelines when submitting to scientific journals across all areas of medicine. Relatedly, risk of bias (ROB) tools (eg, Cochrane ROB, ${ }^{9}$ Jadad Scale ${ }^{10}$ ) evaluate 
RCT research conduct. Numerous reviews have evaluated reporting quality and conduct of medical (eg, surgical, ${ }^{11}$ medical device ${ }^{12}$ and pharmacological ${ }^{13}$ interventions) RCTs. Only a few previous systematic reviews have assessed the quality of exercise RCT reporting and conduct. ${ }^{14-18}$ However, these reviews were limited in scope (eg, did not use comprehensive guidelines like CONSORT and Cochrane ROB; included a small number of trials) and incompletely reported key aspects of study methods (eg, item rating criteria, reviewer training). To our knowledge, no exercise reviews have contextualised their findings via direct comparison with trials in other research disciplines.

Therefore, our primary objective was to comprehensively evaluate the overall quality of exercise RCT reporting and conduct in clinical populations. The primary outcome was overall quality score (ie, the combined quality scores from three research reporting and two research conduct inventories). We also compared the quality of research reporting and conduct from exercise RCTs with matched RCTs of pharmacological therapies (a well-established field of biomedical research with a long history of adopting RCT methods) ${ }^{19}$ using (1) the complete guidelines and (2) only key items from the guidelines (ie, those generally applicable to both intervention types) to

\section{Round 1: Exercise Trials}

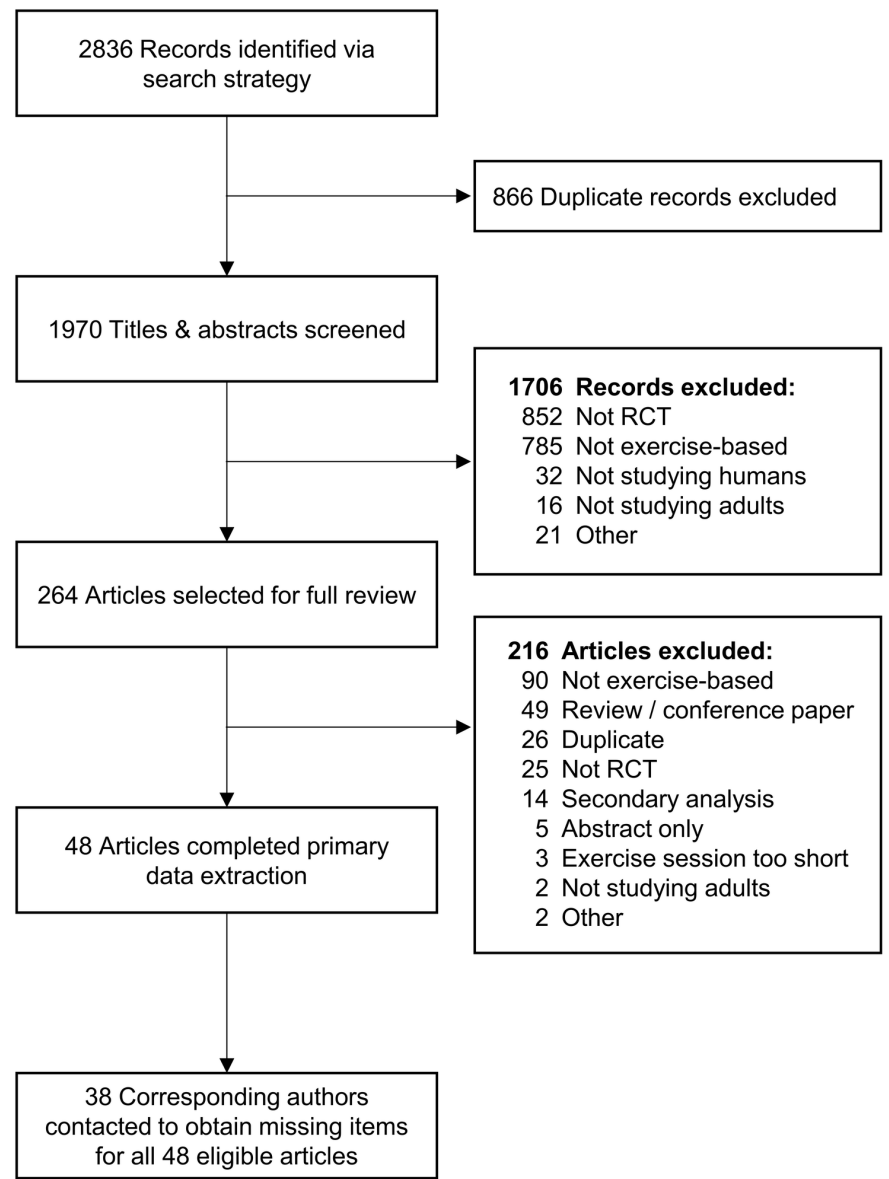

provide context for our findings. Secondary objectives were to compare individual items within the research reporting and conduct inventories as well as to examine factors associated with overall quality score.

\section{METHODS}

\section{Search strategy}

This review was conducted in accordance with the Preferred Reporting Items for Systematic Reviews and Meta-Analyses (PRISMA) ${ }^{20}$ and AMSTAR $2^{21}$ guidelines (online supplemental methods 1 and 2). Full study methods are provided within online supplemental methods 3-7 and online supplemental table 1. Briefly, a research informationist (KM) conducted two sequential literature searches for exercise (first search) and pharmacological (second search) RCTs within the Embase (Elsevier), PubMed (NLM) and CINAHL (EBSCO) databases (figure 1). The search for exercise RCTs was conducted using a combination of relevant keywords and controlled vocabulary: (1) exercise training intervention and (2) RCTs. The search was restricted to trials published between 1 January 2008 (the year the CONSORT extension for non-pharmacological treatments (CONSORT-NPT) was first published ${ }^{22}$ and the search date (8 March 2018).

\section{Round 2: Pharmacological Trials}

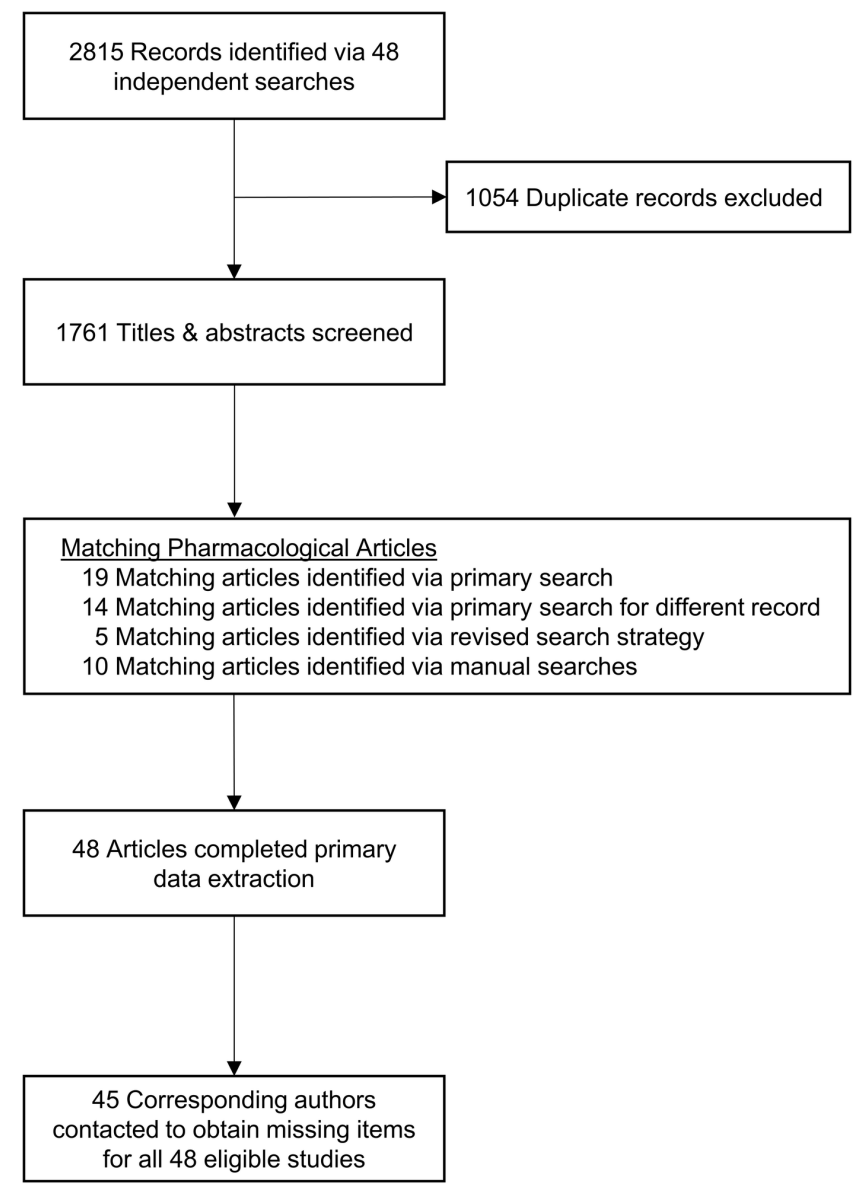

Figure 1 Preferred Reporting Items for Systematic Reviews and Meta-Analyses flow diagram. RCT, randomised controlled trial. 
Meta-data (ie, journal, cohort/population, sample size and number of study sites) were extracted for eligible exercise RCTs and used to define the matching criteria for pharmacological RCTs. The pharmacological RCT search was conducted on 20 November 2018. The search was similarly restricted by date (1 January 2008-20 November 2018) and used a combination of relevant search terms and matching criteria for: (1) pharmaceutical intervention, (2) RCTs, (3) journal, (4) cohort/ population, and (5) number of study sites (single or multicentre). We purposefully restricted our search to medical journals with impact factors $\geq 15$ because journals with higher impact factors are more likely to endorse and enforce reporting quality guideline ${ }^{23-25}$ and publish both exercise and pharmacological RCTs-leading to a more balanced foundation for comparison between study types.

\section{Study eligibility criteria}

Exercise RCTs involving adults ( $\geq 18$ years of age) with chronic conditions, written in English, and published in journals with impact factors $\geq 15$ according to the 2016 Journal Citation Reports (Clarivate Analytics) between 1 January 2008 and the search dates (exercise: 8 March 2018; pharmacological: 20 November 2018) were eligible. Exercise therapy interventions were defined as those involving chronic ( $>3$ weeks), repeated sessions of supervised (in person, with or without a distance-based component) aerobic training (ie, endurance activity, $\geq 15 \mathrm{~min} /$ session), resistance training (ie, multiple large muscle group exercises involving repeated voluntary muscle contractions against a resistance greater than those normally encountered in activities of daily living), or the combination, with the objective of improving healthrelated outcomes. ${ }^{26}{ }^{27}$ Pharmacological interventions were defined as studies involving the administration of established or experimental pharmacological agents with the objective of improving health.

\section{Study selection, matching, data extraction and additional sources}

Trained study reviewers (JM and KS; see online supplemental method 3 for training description) independently screened and evaluated identified article titles and abstracts in the DistillerSR web platform (Evidence Partners, Ottawa, Canada; figure 1). Next, full manuscripts of potentially eligible articles were independently reviewed using DistillerSR. Excluded exercise records are listed in online supplemental table $1 .{ }^{28}$ Matching criteria for exercise and pharmacological therapy RCTs included: (1) publishing journal $( \pm 5$ impact factor points according to the 2016 Journal Citation Reports (Clarivate Analytics, formerly ISI Web of Knowledge)), (2) study population (sharing similar disease characteristics), (3) study sample size $( \pm 30 \%$ difference in study sample size), and (4) number of study sites (single vs multisite). These specific matching criteria were selected to establish impartial comparison between exercise and pharmacological RCTs.
The 'publishing journal' criterion was selected because studies published within the same journal should, in theory, be held to similar reporting standards. If no direct match could be identified within the same journal, we used an investigator-defined cut-off of \pm 5 impact factor points to find alternate matches because impact factor has been shown to be associated with RCT reporting and methodological quality. ${ }^{29}{ }^{30}$ The 'study population' criterion was chosen to account for differences in the research methods and standards across specific clinical populations and specialties. If no direct population match could be identified, we considered closely related populations. For example, for trials among patients with cardiac diseases, cardiomyopathy or heart failure was considered surrogate. We selected the 'study sample size' and 'number of study sites' as criteria to control for differences in the methods (eg, human and physical resources, infrastructure) used to conduct smaller versus larger trials. To this end, an investigator-defined cut-point of a $30 \%$ difference in sample size was used to match RCTs of similar scale and logistical complexity. Exercise and pharmacological therapy RCTs had to be matched on a minimum of two of the four matching criteria to be eligible. The pharmacological therapy RCT with values closest to the target exercise RCT was used if more than one potential match was identified. Full data were extracted for all eligible RCTs from the primary article and all other publicly available supplemental data sources using DistillerSR and Reference Guides. Disagreements concerning eligibility, data extractions, and ROB assessments were resolved by consensus (JM and KS) and adjudicated by a third party (SCA) when consensus could not be obtained. The corresponding author for each article was contacted by investigators (SCA, JMS, LWJ) to request information on incomplete and missing items. After 4 weeks, non-responding authors were recontacted and provided an additional $\sim 4$ weeks to respond. Reporting totals were revised after the closure of data collection (ie, final author contact (1 September 2019)).

\section{Evaluation measures}

Each trial was evaluated on two sets of criteria: (1) quality of research reporting and (2) quality of research conduct using complete standardised inventories and/or key items from these inventories, as needed. Exercise RCTs were evaluated on a maximum of 78 potential items and pharmacological RCTs were evaluated on a maximum of 63 potential items. The quality of exercise research reporting was first assessed using CONSORT-NPT (52 items $),{ }^{6}$ CONSORT-Harms $(10 \text { items })^{31}$ and TIDieR (16 items). ${ }^{8}$ The quality of pharmacological research reporting was assessed using CONSORT $\left(37 \mathrm{items}^{7}\right)$ and CONSORT-Harms (10 items). However, there are no TIDieR-equivalent guidelines available to assess pharmacological intervention reporting. Therefore, intervention reporting for pharmacological interventions was assessed using six key items from TIDieR (including intervention length, modality, location, frequency, dose and 
adherence). Exercise dose consisted of session intensity and duration (aerobic and resistance interventions) as well as the number of sets and repetitions (resistance interventions only). Exercise RCT reporting was also re-evaluated using just the 37 items from the CONSORT guidelines that are common to both intervention types. ${ }^{7}$ Notably, there were items within the CONSORT-based reporting quality guidelines (and TIDieR guidelines for exercise RCTs) that were not applicable (NA) based on the unique aspects of individual exercise and pharmacological RCTs. Items rated as NA were excluded from the calculation of primary and secondary outcomes for each study (see the Endpoints and Data analysis sections). All research reporting quality items were rated (with equal weighting and maximum score of 1 point per item) as: $1=$ "properly reported' or $0=$ 'unclear' (incompletely reported); or 'not reported' (missing); NA='not applicable'.

The quality of research conduct was assessed using the Cochrane ROB inventory $\left(7\right.$ items $\left.^{9}\right)$ and the Jadad Scale (3 items).${ }^{10}$ Cochrane ROB items were rated (with equal weighting) as: $2=$ 'low risk of bias'; $1=$ 'unclear risk of bias' or $0=$ 'high risk of bias'. The first two items in the Jadad Scale were scored as 2='low risk of bias' or $0=$ "high risk of bias'; and the third item was scored as $1=$ 'low risk of bias' or $0=$ 'high risk of bias.'

\section{Endpoints}

The primary endpoint was overall quality score defined as the sum of numerical quality scores from all research reporting and conduct inventories relative to the total number of applicable items. Secondary endpoints were defined as the numerical quality scores for each research reporting guideline and conduct inventory relative to the total number of applicable items for the study.

\section{Data analysis}

Characteristics of RCTs were summarised using descriptive statistics. Quality scores were calculated and reported in numerical and percentage score formats. Percentage quality scores were calculated for the primary endpoint (overall quality score) and secondary endpoints (individual scores for the quality of reporting guidelines and quality of conduct inventories) as the achieved score relative to the total number of applicable items per RCT. All items from the two research conduct inventories were applicable for every study and scored with values of 0.1 or 2 resulting in total quality score for research conductrelated items of 19 per study. The variation in the total number of applicable items per study was caused by different numbers of reporting quality guideline items being rated as 'NA', resulting in median numbers of eligible items (ie, denominators for percentage score calculations) of 80 for exercise RCTs and 68 for pharmacological RCTs. Generalised linear models (GLMs) were specified with a binomial family and logit link to compare the scores of exercise and pharmacological RCTs. For the quality of research conduct scales (Cochrane ROB, Jadad Scale), item ratings were analysed as low or unknown risk of bias versus high risk of bias. The model accounts for differences in the number of eligible items and the matching between the exercise and pharmacological RCTs. GLMs were also used to evaluate factors associated with overall quality scores for exercise and pharmacological therapy RCTs separately. Potential factors included journal impact factor ( $<25$ vs $\geq 25$ ), RCT sample size ( $<152$ vs $\geq 152$ participants), number of study sites (single vs multiple sites) and year of publication ( $<2013 \mathrm{vs}$ $\geq 2013$ ). Cut-offs for impact factor, sample size and year of publication were based on the medians. Exploratory oneway analyses of variance (ANOVAs) were used to assess whether reporting quality varied across studies matched on $50 \%, 75 \%$ and $100 \%$ of matching criteria. For comparisons of the individual components of the composite scores, $\mathrm{p}$ values were adjusted for multiple comparisons within research reporting and conduct inventories using a Bonferroni correction. Data are presented as median (IQR) and OR (95\% CIs). Inter-rater reliability was evaluated using intraclass correlation coefficient (ICC) calculated via one-way ANOVA. ${ }^{32}$ Analyses were performed using R V.4.0.2. ${ }^{33}$

\section{Patient and public involvement}

Patients were not included in the design and conduct of this review. However, optimising patient safety and benefit is the fundamental purpose of this review. Specifically, the proximal objective of the review is to identify opportunities to improve the rigour and reproducibility of exercise research that, in turn, will facilitate the delivery of robust evidence-based exercise interventions across diverse clinical populations and settings.

\section{RESULTS}

See online supplemental tables 2-12 for full study characteristics and results. A total of 2836 potential exercise records were identified with 866 duplicate records removed using EndNote citation management software (Clarivate Analytics). A total of 1970 records underwent title and abstract screening (figure 1). Of these, 264 records underwent full review with 48 exercise RCTs meeting eligibility criteria. ${ }^{34-81}$ The 48 primary searches for pharmacological therapy trials produced 2815 records. The median number of records returned per search was 15 (range: 0-853). Review of the primary search results produced 19 matched pharmacological RCTs; the remaining 29 pharmacological RCTs were identified via review of modified secondary searches. ${ }^{82-129}$ Overall, 13 pairs of exercise and pharmacological RCTs were matched on $100 \%$ of our four matching criteria, 18 pairs of RCTs were matched on $75 \%$, and 17 pairs of RCTs were matched on $50 \%$. On average, exercise and pharmacological therapy RCTs were matched on three of four criteria. The results of agreement for the two raters' assessments for the exercise and pharmaceutical studies publication scores were: overall quality score: ICC $=0.85$ (95\% CI: 0.78 to 0.89 ); quality of research reporting guidelines: ICC $=0.83$ (95\% CI: 
0.75 to 0.88$)$; and quality of research conduct inventories: ICC $=0.73$ (95\% CI: 0.62 to 0.81$)$.

\section{Missing information (author contact)}

Each RCT had missing information. The median number of eligible reporting quality items for exercise RCTs was 61 (IQR: 59-62) and pharmacological RCTs was 49 (IQR: 48-50). The median percentage (numerical; numerical range) of missing or indeterminate reporting quality items in exercise RCTs was $46 \%$ (28 of 61 items; 13-49) compared with 27\% (13 of 49 items; 5-26) in pharmacological RCTs. Sixteen (33\%) and seven (15\%) corresponding authors of the exercise and pharmacological RCTs responded with a median of 12.5 (IQR: 10.0-16.2) and 5.0 (IQR: 4.0-6.5) additional items.

\section{RCT characteristics}

RCT characteristics are summarised in table 1. Exercise therapy RCTs included a total of 11658 participants (7411 $(64 \%)$ were allocated to experimental arms; including studies with 1-3 intervention arms) compared with 18 501 participants (11 909 (64\%) allocated to experimental arms) in the pharmacological therapy RCTs. The median sample sizes of exercise RCTs were 138 (IQR: 100-236) and 160 (IQR: 98-314) for pharmacological RCTs. Overall, 34 of 48 exercise RCTs (71\%) and 31 of 48 pharmacological RCTs (65\%) reported positive primary outcomes.

\section{Primary and secondary endpoints}

The median overall quality score for RCTs of exercise therapy was $58 \%$ (46 of 80; IQR: 49-65) compared with $77 \%$ (53 of 68; IQR: 71-84; $\mathrm{p} \leq 0.001$ ) for pharmacological therapy RCTs (table 2). For secondary endpoints, median research reporting quality scores across all complete guidelines were significantly lower in exercise RCTs in comparison with pharmacological RCTs (table 2). The lowest scoring research reporting quality guideline was CONSORT-Harms for both exercise and pharmaceutical studies. In exercise RCTs, median CONSORT-Harms score was 32\% (3 of 9; IQR: 11-51) compared with 67\% (6 of 10; IQR: 40-73) in pharmacological RCTs ( $\mathrm{p} \leq 0.001$; table 2$)$. Harms reporting was missing entirely from 19\% (9 of 48) of exercise RCTs and $4 \%$ (2 of 48) of pharmacological RCTs. Exercise RCTs reported 57\% (8 of 15; IQR: 7-10) of TIDieR items (table 2). Over $75 \%$ of exercise RCTs were missing details related to intervention personnel, progression and participant adherence (table 3).

In exercise RCTs, median Cochrane ROB score was $71 \%$ (10 of 14; IQR: 64-79) compared with 93\% (13 of 14; IQR: 86-93) in pharmacological RCTs ( $\mathrm{p} \leq 0.001$; table 2$)$. A summary of Cochrane ROB assessments for individual exercise and pharmacological therapy RCTs is provided in table 4. Exploratory one-way ANOVAs did not indicate a difference in reporting quality outcomes between exercise and pharmacological RCTs matched on $50 \%, 75 \%$ or $100 \%$ of the matching criteria.
Table 1 Characteristics of exercise and pharmacological therapy RCTs

\begin{tabular}{|c|c|c|}
\hline Characteristic & $\begin{array}{l}\text { Exercise } \\
\text { therapy RCTs* } \\
\text { no (\%) }\end{array}$ & $\begin{array}{l}\text { Pharmacological } \\
\text { therapy RCTs } \\
\text { no }(\%)\end{array}$ \\
\hline \multicolumn{3}{|l|}{ Journal (impact factors $\ddagger$ ) } \\
\hline $\begin{array}{l}\text { Annals of Internal Medicine } \\
(19.315)\end{array}$ & $2(4.2)$ & $4(8.3)$ \\
\hline $\begin{array}{l}\text { British Medical Journal } \\
(27.604)\end{array}$ & $1(2.1)$ & $0(0)$ \\
\hline Circulation (23.054) & $0(0)$ & $2(4.2)$ \\
\hline $\begin{array}{l}\text { European Heart Journal } \\
(24.889)\end{array}$ & $4(8.3)$ & $4(8.3)$ \\
\hline European Urology (17.298) & $3(6.2)$ & $3(6.2)$ \\
\hline Gastroenterology (19.809) & $0(0)$ & $2(4.2)$ \\
\hline Gut (17.943) & $1(2.1)$ & $0(0)$ \\
\hline $\begin{array}{l}\text { Journal of the American } \\
\text { College of Cardiology } \\
\text { (18.639) }\end{array}$ & $7(15)$ & $7(15)$ \\
\hline $\begin{array}{l}\text { Journal of the American } \\
\text { Medical Association (JAMA; } \\
51.273 \text { ) }\end{array}$ & $12(25)$ & $9(19)$ \\
\hline $\begin{array}{l}\text { JAMA Internal Medicine } \\
(20.768)\end{array}$ & $2(4.2)$ & $1(2.1)$ \\
\hline JAMA Oncology (22.416) & $1(2.1)$ & $0(0)$ \\
\hline $\begin{array}{l}\text { Journal of Clinical Oncology } \\
(28.349)\end{array}$ & $11(23)$ & $13(27)$ \\
\hline Lancet (59.102) & $0(0)$ & $1(2.1)$ \\
\hline $\begin{array}{l}\text { New England Journal of } \\
\text { Medicine (70.670) }\end{array}$ & $4(8.3)$ & $2(4.2)$ \\
\hline \multicolumn{3}{|l|}{ Journal impact factor } \\
\hline Overall (median (IQR)) & $28(19-51)$ & $28(19-34)$ \\
\hline \multicolumn{3}{|l|}{ Number of sites } \\
\hline Single & $33(69)$ & $15(31)$ \\
\hline Multicentre & $15(31)$ & $33(69)$ \\
\hline \multicolumn{3}{|l|}{ Sample size } \\
\hline Overall (median (IQR)) & 138 (100-236) & $160(98-314)$ \\
\hline \multicolumn{3}{|l|}{ Year of publication } \\
\hline$<2013$ & $24(50)$ & $17(35)$ \\
\hline$\geq 2013$ & $24(50)$ & $31(65)$ \\
\hline Author response & $16(33)$ & $7(15)$ \\
\hline
\end{tabular}

${ }^{*} \mathrm{n}=48$ exercise therapy RCTs.

$\dagger \mathrm{n}=48$ pharmacological therapy RCTs.

$\ddagger$ Clarivate (2018).

$\mathrm{RCTs}$, randomised controlled trials.

\section{Comparison of key items}

Thirty-seven of 52 CONSORT items, all 10 CONSORTHarms items, and 6 of 16 TIDieR items were considered key items. Median reporting scores for the key items from CONSORT and TIDieR were not significantly different between exercise and pharmacological RCTs; whereas, reporting scores for CONSORT-Harms were significantly lower for exercise RCTs (table 2). 
Table 2 Quality of exercise and pharmacological therapy RCT reporting and conduct

\begin{tabular}{|c|c|c|c|c|c|}
\hline \multirow{2}{*}{ Outcomes } & \multicolumn{2}{|c|}{ Exercise RCTs* } & \multicolumn{2}{|c|}{ Pharmacological RCTs $†$} & \multirow{2}{*}{$P$ valueł } \\
\hline & Median & IQR & Median & IQR & \\
\hline \multicolumn{6}{|l|}{ Primary outcome } \\
\hline Overall quality score & 45.5 & $38.8-51.2$ & 52.5 & $46.8-58.0$ & $<0.001$ \\
\hline Eligible score§ & 80.0 & $78.0-81.0$ & 68.0 & $67.0-69.0$ & \\
\hline Per cent & 58.2 & $48.6-64.5$ & 77.1 & $70.5-83.9$ & \\
\hline \multicolumn{6}{|l|}{ Secondary outcomes } \\
\hline \multicolumn{6}{|c|}{ Research reporting: complete guidelines } \\
\hline CONSORT score & 25.0 & $23.0-28.0$ & 25.0 & $22.0-28.0$ & $<0.001$ \\
\hline Eligible scoreף & 45.0 & $44.0-47.0$ & 33.0 & $32.0-34.0$ & \\
\hline Per cent & 56.8 & $50.0-62.8$ & 75.4 & $69.7-84.7$ & \\
\hline CONSORT-Harms score & 3.0 & $1.0-5.0$ & 6.0 & $4.0-7.2$ & $<0.001$ \\
\hline Eligible score ${ }^{\star \star}$ & 9.0 & $9.0-10.0$ & 10.0 & $10.0-10.0$ & \\
\hline Per cent & 31.7 & $11.1-51.4$ & 66.7 & $40.0-72.5$ & \\
\hline TIDieR score & 8.0 & $7.0-10.0$ & - & - & - \\
\hline Eligible score†† & 15.0 & $14.0-15.0$ & - & - & \\
\hline Per cent & 57.4 & $49.2-67.9$ & - & - & \\
\hline Research reporting: key items & & & & & 0.68 \\
\hline CONSORT score & 24.0 & $21.0-27.0$ & 26.5 & $22.8-28.0$ & \\
\hline Eligible score & 31.0 & $30.0-32.0$ & 33.0 & $32.0-34.0$ & \\
\hline Per cent & 75.4 & $68.0-84.8$ & 79.4 & $70.7-85.7$ & \\
\hline Intervention score & 4.0 & $3.0-4.0$ & 4.0 & $4.0-4.2$ & 0.03 \\
\hline Eligible scoreł‡ & 6.0 & - & 6.0 & - & \\
\hline Per cent & 66.7 & $50-66.7$ & 66.7 & $66.7-70.8$ & \\
\hline \multicolumn{6}{|l|}{ Research conduct inventories } \\
\hline Cochrane ROB score & 10.0 & $9.0-11.0$ & 13.0 & $12.0-13.0$ & $<0.001$ \\
\hline Eligible score§§ & 14.0 & - & 14.0 & - & \\
\hline Per cent & 71.4 & $64.3-78.6$ & 92.9 & $85.7-92.9$ & \\
\hline Jadad score & 3.0 & $2.8-5.0$ & 5.0 & $4.0-5.0$ & $<0.001$ \\
\hline Eligible scoreףी & 5.0 & - & 5.0 & - & \\
\hline Per cent & 60.0 & $55.0-100.0$ & 100.0 & $80.0-100.0$ & \\
\hline
\end{tabular}

${ }^{*} \mathrm{n}=48$ exercise therapy RCTs.

$\dagger \mathrm{n}=48$ pharmacological therapy RCTs.

$\ddagger \mathrm{P}$ values were adjusted for multiple comparisons within research reporting and within research conduct inventories using a Bonferroni correction.

§Maximum possible quality score: overall quality for exercise therapy RCTs=87 and pharmacological therapy $\mathrm{RCTs}=72$.

ףMaximum possible quality score: CONSORT-NPT for exercise therapy RCTs=52; CONSORT for pharmacological therapy RCTs=37.

**Maximum possible quality score: CONSORT-Harms for all RCTs $=10$.

††Maximum possible quality score: TIDieR for exercise RCTs $=16$.

$\ddagger$ Maximum possible quality score: intervention for all RCTs $=6$.

$\S \S$ Maximum possible quality score: Cochrane ROB for all RCTs=14.

ๆीMaximum possible quality score: Jadad Scale for all RCTs $=5$.

CONSORT, Consolidated Standards of Reporting Trials; CONSORT-NPT, CONSORT for non-pharmacological treatments; RCT,

randomised controlled trial; ROB, risk of bias; TIDieR, Template for Intervention Description and Replication.

Compared with pharmacological RCTs, exercise RCTs had lower reporting of key study methods (eg, blinding after group assignment ( $60 \%$ vs $98 \%$ ), balanced discussion of harms vs benefits ( $39 \%$ vs $66 \%$ ), intervention modality (39\% vs $66 \%)$, intervention dose $(50 \%$ vs $98 \%)$, and complete intervention descriptions $(0 \%$ vs $67 \%)$ ).
Factors associated with reporting quality

Journal impact factor $\geq 25$ (OR: 1.36 ; $95 \%$ CI: 1.18 to 1.57), larger sample size $\geq 152$ (OR: 1.29 ; $95 \%$ CI: 1.11 to 1.51 ), and more recent publication year $\geq 2013$ (OR: 1.18; $95 \%$ CI: 1.03 to 1.34 ) were associated with higher overall quality scores in exercise RCTs (table 5). The only factor associated with greater overall quality scores 


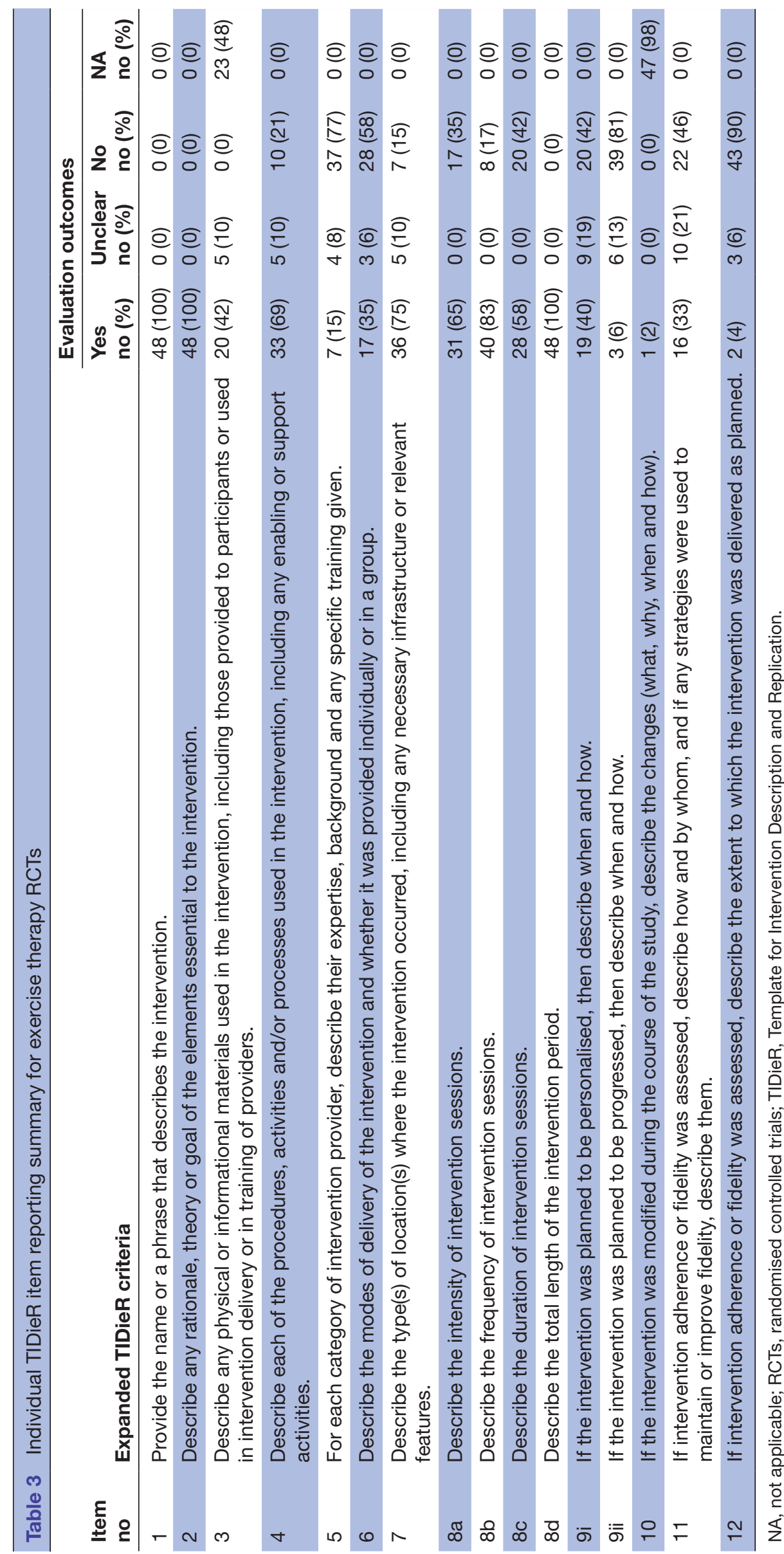




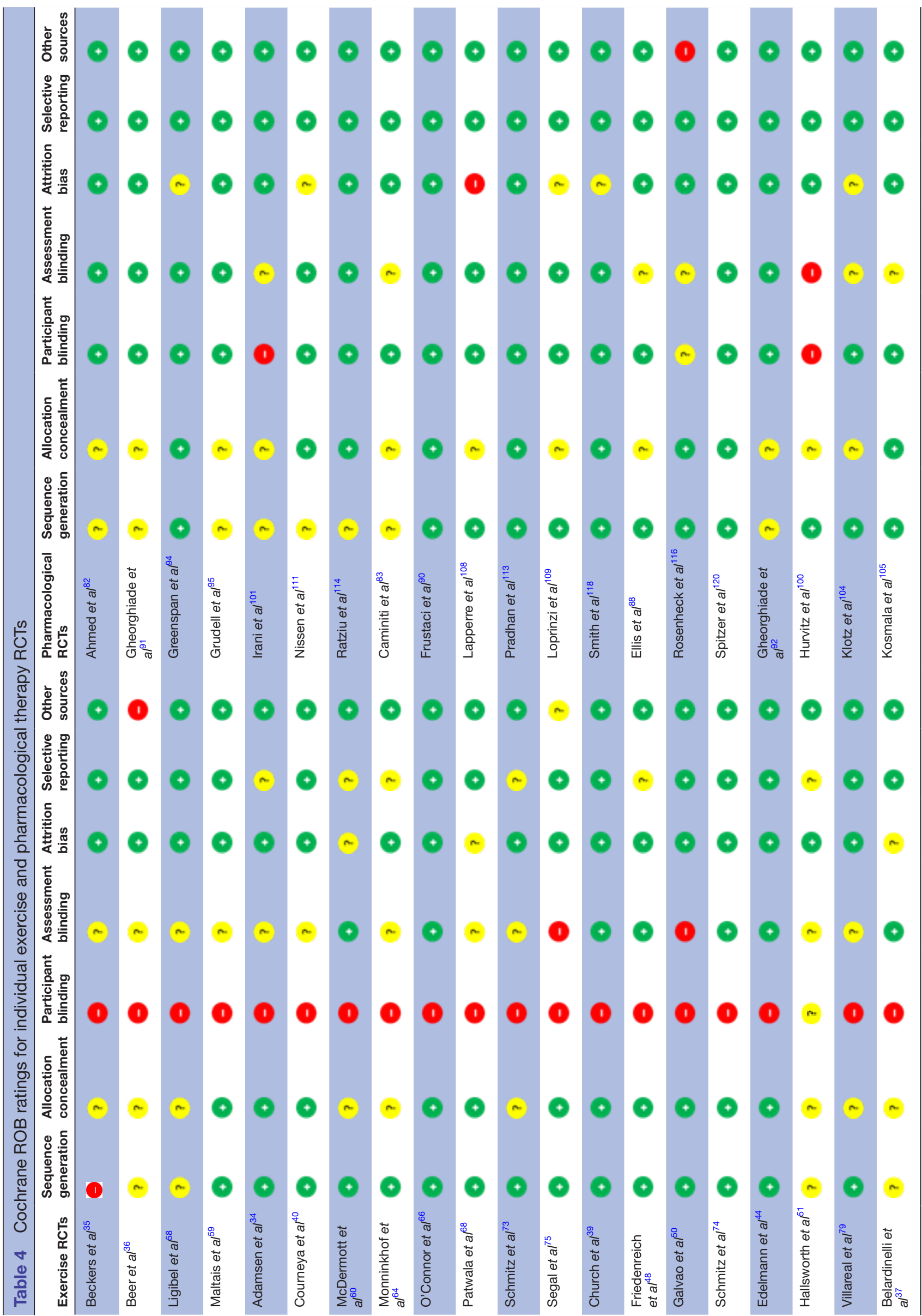

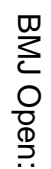




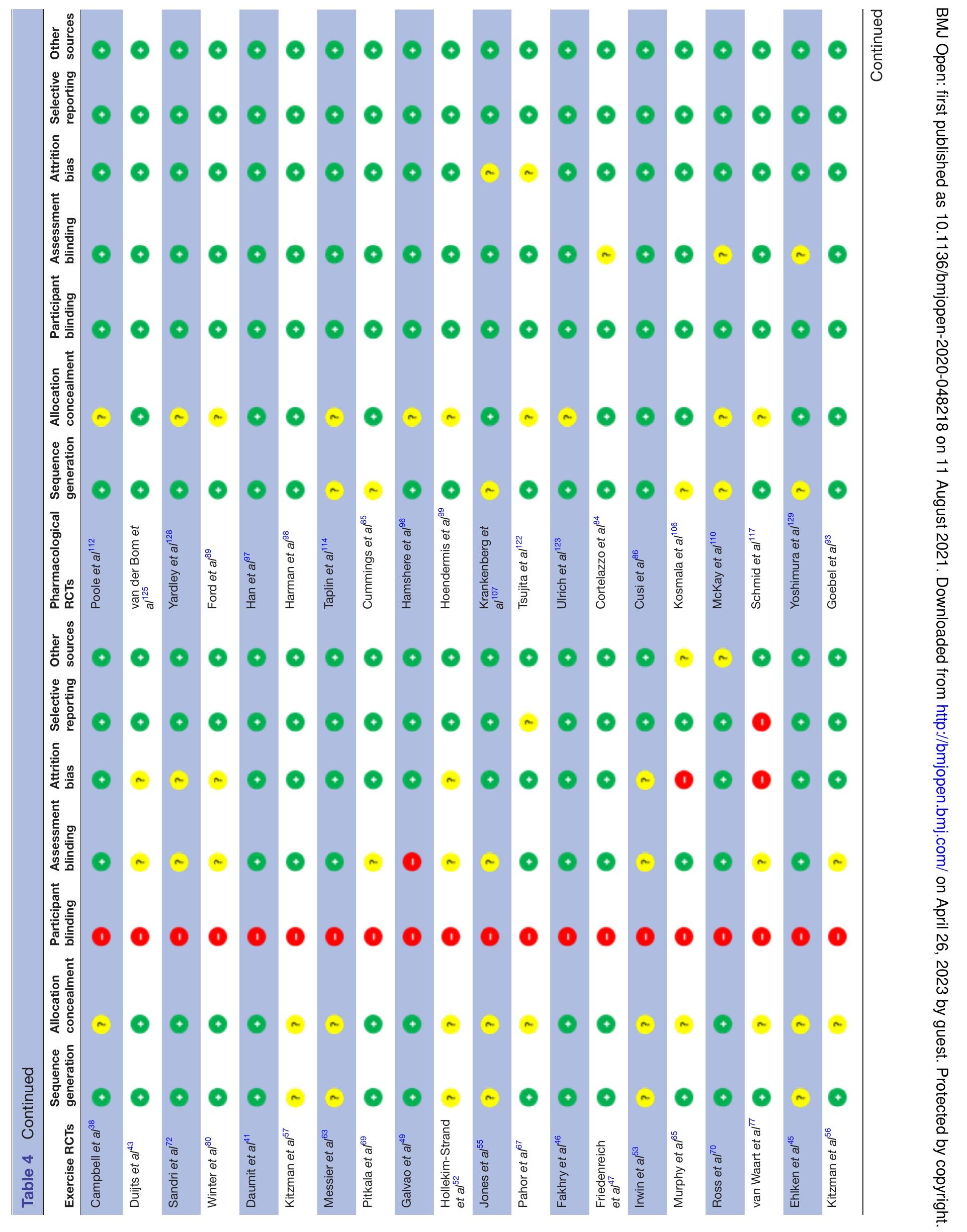


Open access

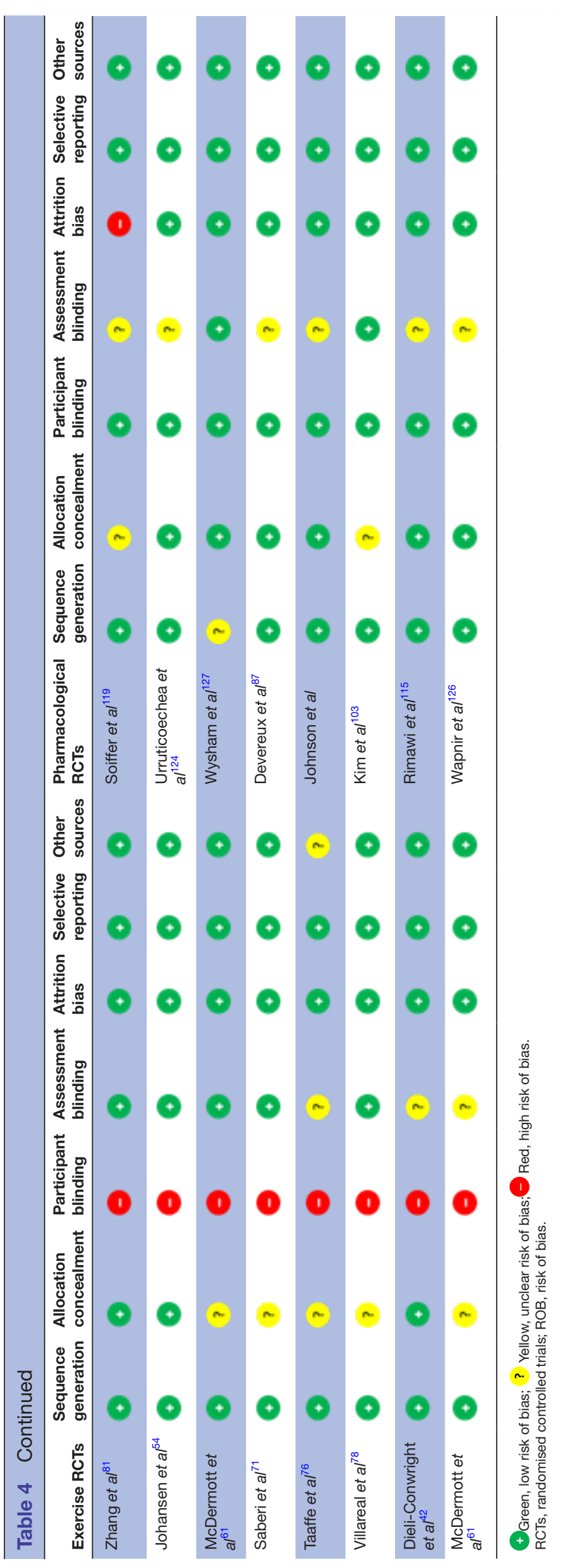

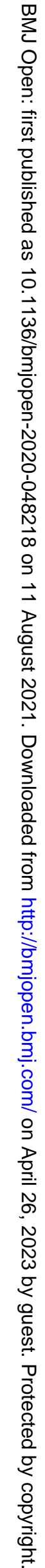

10

Adams SC, et al. BMJ Open 2021;11:e048218 do i:10,1136 bmpen-2020-048218 
Table 5 Factors associated with overall quality score, stratified by study type

\begin{tabular}{|c|c|c|c|c|c|c|c|c|}
\hline Outcome & $\begin{array}{l}\text { Study } \\
\text { characteristics }\end{array}$ & $\begin{array}{l}\text { Analysis } \\
\text { dichotomy }\end{array}$ & \multicolumn{3}{|c|}{ Exercise therapy RCTs* } & \multicolumn{3}{|c|}{$\begin{array}{l}\text { Pharmacological therapy } \\
\text { RCTs† }\end{array}$} \\
\hline \multirow{3}{*}{$\begin{array}{l}\text { Overall quality } \\
\text { score }\end{array}$} & Impact factor & $\geq 25$ vs $<25$ & 1.36 & 1.18 to 1.57 & $<0.001$ & 1.02 & 0.84 to 1.24 & 0.80 \\
\hline & Sample size & $\geq 152$ vs $<152$ & 1.29 & 1.11 to 1.51 & 0.001 & 1.20 & 0.97 to 1.47 & 0.089 \\
\hline & Number of sites & Multicentre vs single centre & 1.08 & 0.92 to 1.27 & 0.30 & 1.21 & 0.98 to 1.49 & 0.078 \\
\hline
\end{tabular}

${ }^{*} \mathrm{n}=48$ exercise therapy RCTs.

$\dagger \mathrm{n}=48$ pharmacological therapy RCTs.

$\mathrm{RCTs}$, randomised controlled trials.

in pharmacological RCTs was more recent publication year $\geq 2013$ (OR: $1.35 ; 95 \%$ CI: 1.14 to 1.60 ; $\mathrm{p}<0.001$ ).

\section{DISCUSSION}

We evaluated the quality of research reporting and conduct within exercise therapy RCTs in clinical populations, then compared with the quality of reporting and conduct in matched pharmacological therapy RCTs. Our findings demonstrate that the quality of exercise therapy RCT reporting and conduct is suboptimal according to all complete guidelines and inventories used in this study and is inferior to RCTs of pharmacological therapy. However, the mean overall reporting quality for RCT methods and interventions, but not harms, was similar between intervention types when considering key items within the respective guidelines.

To our knowledge, five systematic reviews ${ }^{14-18}$ have evaluated the overall quality of research reporting and conduct within exercise RCTs in clinical populations. Our findings corroborate the findings of these systematic reviews demonstrating the overall quality of exercise RCT reporting and conduct is suboptimal. For instance, in 27 exercise RCTs involving 1467 patients with metabolic syndrome, Ostman $e t a l^{17}$ reported a median overall quality of $60 \%$ (range: $33 \%-87 \%$ ) using the Tool for the assEssment of Study qualiTy and reporting in EXercise E $^{130}$ guideline. Similarly, Borror et $\mathrm{al}^{14}$ evaluated 12 exercise RCTs (representing 135 patients) with type 2 diabetes using a combination of 16 items from CONSORT, Jadad, Physiotherapy Evidence Database guidelines ${ }^{131}$ and the Delphi list. ${ }^{132}$ The combined trial reporting and conduct quality score was $49 \%$ (range: $38 \%-58 \%$ ). Nevertheless, prior reviews have several important limitations. For instance, these reviews ${ }^{14-18}$ did not use the complete versions of comprehensive and widely accepted guidelines (eg, CONSORT, Cochrane ROB) and, thus, did not rigorously evaluate the quality of all salient aspects of trial reporting and conduct. In addition, the number of exercise trials evaluated was small, comparisons of reporting with matched pharmacological trials were not performed, and no data extraction training or standardisation was described within these studies. Thus, our review that was conducted by well-trained independent reviewers using specialised reference guides to facilitate standardised data extraction according to five distinct but complementary established guidelines/tools to assess and compare a large number of exercise trials and matched pharmacological trials provides the most rigorous evaluation of exercise research quality to date.

Although overall quality scores were poor in RCTs of exercise therapy, these findings were generally driven by poor research reporting quality scores across select individual guidelines rather than suboptimal RCT conduct per se. Foremost among these, the finding that harms were the most poorly reported aspects of exercise RCTs is concerning. Previous reviews in patients with cancer, ${ }^{133}$ chronic fatigue, ${ }^{134}$ and multiple sclerosis ${ }^{135}$ have specifically focused on evaluating the reporting of adverse event frequency and descriptions; this information was completely missing within $23 \%-88 \%$ of included exercise trials. ${ }^{133-135}$ Our study extends these findings by demonstrating that harms-related monitoring and reporting were missing or incompletely reported in $\geq 75 \%$ of exercise RCTs; and, relatedly, $>50 \%$ of articles failed to provide a balanced discussion of risks to benefits for the tested interventions. In contrast, a related assessment of 325 chemotherapy trials reported a mean CONSORT-Harms score of $63 \%,{ }^{136}$ compared with mean harms scores of 36\% (exercise RCTs) and 57\% (pharmacological RCTs) in our study. Based on our findings, we cannot support or refute the prevailing dogma that exercise is a safe and tolerable intervention strategy in most areas of clinical medicine. ${ }^{1}$ However, it is not possible to fully evaluate the harms to benefit ratio of exercise without accurate monitoring and reporting of adverse events within exercise RCTs - a critical consideration in the clinical recommendation of any medical intervention.

Reporting of intervention methods is the most commonly assessed quality metric in exercise RCTs to date. Our findings support previous reviews of exercise interventions in patients with peripheral arterial disease ${ }^{137}$ cancer, ${ }^{138}$ hypertension ${ }^{139}$ and recovering from stroke $^{140}$ demonstrating essential elements, including details on the exercise prescription regimen itself, are 
incompletely reported. For example, Hacke et al used TIDieR to assess intervention reporting quality in 24 exercise RCTs involving 1195 patients with hypertension and reported that $91 \%$ of exercise intervention studies were missing information about intervention supervisors and $52 \%$ were missing details of intervention adherence. ${ }^{139}$ Relatedly, Tew et al also used TIDieR and reported that $20 \%-26 \%$ of reports failed to describe several of the most fundamental exercise intervention elements (ie, exercise mode, intensity, tailoring and progression) in 58 exercise RCTs in patients with peripheral arterial disease ${ }^{137}$ In our study, information on patient compliance to the planned exercise regimen as well as the expertise of the individuals implementing the intervention was missing or incomplete in $>90 \%$ of trials; fundamental details pertaining to dose of prescribed exercise were also missing in $50 \%$ trials. By contrast, pharmacological intervention compliance was similarly missing in $\sim 80 \%$ of trials; however, prescribed pharmacotherapy dose was only missing in $2 \%$ of studies. Incomplete intervention description not only hinders study reproducibility and cross-study integration (for meta-analyses) but also precludes quantification of exercise and pharmacotherapy dose-a key metric for elucidation of dose/exposure-response relationships and translation into clinical practice. ${ }^{141}$

A major strength of this review is that, to our knowledge, it is the first to compare the quality of research reporting and conduct within exercise and pharmacological therapy RCTs. We used rigorous data extraction and evaluation processes to provide the first direct evidence that the quality of research reporting and conduct within exercise RCTs is inferior to similar pharmacological RCTs using the complete reporting guidelines (CONSORT and CONSORT-NPT). For context, the reporting quality of pharmacological RCTs in our review is comparable with previous reviews. For example, using CONSORT, Peron et $a l^{142}$ found that reporting quality of pharmacological RCTs in oncology ranged from $72 \%$ to $74 \%$. A similar review conducted by Ritchie et al reported a CONSORT score of $72 \%$ in 57 pharmacological RCTs (33\% of studies involved patients with metabolic and cardiorespiratory diseases) ${ }^{13}$ Our findings are consistent with these studies and suggest that comparable research reporting quality scores for exercise RCTs are, on average, 15\%-20\% lower. There were no differences observed in mean overall reporting quality when comparing exercise and pharmacological RCTs according to key items from the CONSORT guidelines; however, the reporting of several critical individual items was suboptimal within exercise RCTs (eg, complete intervention descriptions, intervention dose, blinding status). Our findings provide important direction to improve the completeness and rigour of exercise trial reporting.

Several factors may contribute to the lower quality scores for research reporting and conduct within exercise trials. For instance, CONSORT was developed primarily to support the reporting of pharmacological trials and may not adequately capture aspects unique to the conduct of non-pharmacological trials such as exercise. ${ }^{143}$ This issue should have been addressed, in theory, with publication of the CONSORT-NPT extension in $2008 .^{6}{ }^{22}$ Indeed, this extension was developed to facilitate complete reporting across the fundamental aspects of RCTs applicable to all non-pharmacological trials, including exercise. Reporting quality of traditional biomedical therapy RCTs (eg, surgical, pharmaceutical) has improved since the publication of the CONSORT guidelines and superior in journals adopting these guidelines. ${ }^{144-146}$ We similarly found that exercise RCTs published more recently (>2013) had higher overall quality scores. These findings are encouraging and suggest that the awareness and use of established guidelines and inventories to support research reporting and conduct may be increasing, although there remains marked room for improvement. Continued improvement in this context will require continued education of exercise investigators to conform with such guidelines and journals/reviewers hold authors accountable to use of such guidelines. Stricter adherence to CONSORT-NPT, for example, would improve the reporting quality of most fundamental trial aspects; however, this tool may still be too generic to support the comprehensive reporting of features unique to exercise trials, especially intervention description. To this end, adoption of TIDieR, or the more recent exercise-specific Consensus on Exercise Reporting Template guidelines, ${ }^{147}$ is warranted to improve the reporting and reproducibility of exercise interventions within exercise RCTs.

Our study has several limitations. First, the restriction to journals with impact factors $\geq 15$ may overestimate the quality of research reporting and conduct within the included exercise and pharmacological therapy RCTs. Relatedly, the exclusion of exercise RCTs published within sports science journals may underestimate the quality of exercise studies. Nevertheless, we felt it was necessary to selectively draw from this subset of journals given they are most likely to publish RCTs of both intervention types and endorse and enforce reporting quality guidelines ${ }^{23-25}$ to impartially compare and contextualise our findings. Second, the lack of broadly applicable or unified guidelines to compare across exercise and pharmacological therapy RCTs also merits consideration. Guidelines used to evaluate the quality of RCT reporting were either different between study types (ie, CONSORT-NPT $^{6}$ vs CONSORT $^{7}$ ), developed specifically for harms reporting in pharmacological trials, ${ }^{31}$ or investigator-derived given that there are formal standards for non-pharmacological (ie, TIDieR), but not pharmacological, intervention reporting. We controlled for differences in the numbers of evaluable and applicable items across the reporting quality guidelines and used four matching criteria to control the influence of differences in (1) journal editorial standards and policies, (2) population-specific research methods and standards, and (3) the methods, resources, and infrastructure required to conduct smaller versus larger trials. Future research could be strengthened by the establishment of 
standardised matching criteria to facilitate comparisons between branches of biomedical research. Third, we did not update the search following the extraction of the 96 included studies published from 2008 to 2018, which may have introduced bias related to search recency. However, the association between year of publication and reporting quality was evaluated and discussed as herein. Finally, we acknowledge that using non-specific assessment tools (eg, using CONSORT-NPT to evaluate exercise trials or TIDieR to evaluate pharmacological interventions) potentially introduces measurement bias. We limited our evaluations and comparisons to include only reporting and conduct quality items that were applicable to the type of intervention to address this concern and selected 6 of TIDieR's 16 items to facilitate comparisons of intervention reporting quality between exercise and pharmacological RCTs. Development of discipline-specific measurement tools such as CONSORT extensions for acupuncture interventions ${ }^{148}$ and patient-reported outcomes ${ }^{149}$ may be needed to improve reporting of exercise trials.

In summary, the overall quality of research reporting and conduct within exercise RCTs is suboptimal and inferior to pharmacological RCTs. Stricter adherence to established guidelines and inventories is warranted to facilitate the generation of high-quality evidence needed to optimise the safety, efficacy and implementation of exercise therapy in clinical populations.

\section{Author affiliations}

${ }^{1}$ Department of Cardiology, Toronto General Research Institute, Toronto, Ontario, Canada

${ }^{2}$ Ted Rogers Cardiotoxicity Prevention Program, Peter Munk Cardiac Centre, Toronto, Ontario, Canada

${ }^{3}$ Kinesiology and Physical Education, University of Toronto, Toronto, Ontario, Canada ${ }^{4}$ Albert Einstein College of Medicine, Bronx, New York, USA

${ }^{5}$ Internal Medicine, NYU Langone Health, New York, New York, USA

${ }^{6}$ Epidemiology and Biostatistics, Memorial Sloan Kettering Cancer Center, New York, New York, USA

${ }^{7}$ Library, Memorial Sloan Kettering Cancer Center, New York, NY, USA

${ }^{8}$ Anesthesia and Pain Management, Toronto General Hospital, Toronto, Ontario,

Canada

${ }^{9}$ Medicine, Memorial Sloan Kettering Cancer Center, New York, New York, USA

${ }^{10}$ Medicine, Weill Cornell Medical College, New York, New York, USA

Twitter Scott C Adams @DrAdamsSC, Jessica Lavery @jessicalavs, Maggie M Z Chen @maggiecaat, Daniel Santa Mina @DR_SantaMina and Jessica M Scott @ cardiac_fitness

Acknowledgements We would like to thank the corresponding authors for their time and effort in providing us with supplemental information during the author contact phase of the review.

Contributors LWJ conceived the study idea. SCA and JMS coordinated the systematic review. SCA, LWJ and JMS wrote the first draft of the manuscript. KM designed the search strategy. KS and JM screened abstracts and full texts. JM, KS, MMZC and SCA acquired the data. JM, KS and SCA judged risk of bias in the studies. JL and CSM performed the data analyses. SCA, JM, KS, KM, JL, CSM, MMZC, DSM, JMS and LWJ interpreted the data analysis. SCA, JM, KS, KM, JL, CSM, MMZC, DSM, JMS and LWJ critically revised the manuscript. LWJ had full access to all study data and takes responsibility for the integrity of the data and the accuracy of the data analysis. The findings of this study have been presented clearly, honestly, and without fabrication, falsification, or inappropriate data manipulation. LWJ is the guarantor.

Funding LWJ and JMS are supported by research grants from the National Cancer Institute. LWJ and JMS are supported by AKTIV Against Cancer. JL, CSM, JMS and
LWJ are supported by the Memorial Sloan Kettering Cancer Center Support Grant/ Core Grant (P30 CA008748).

Competing interests None declared.

Patient consent for publication Not required.

Provenance and peer review Not commissioned; externally peer reviewed.

Data availability statement All data relevant to the study are included in the article or uploaded as supplemental information.

Supplemental material This content has been supplied by the author(s). It has not been vetted by BMJ Publishing Group Limited (BMJ) and may not have been peer-reviewed. Any opinions or recommendations discussed are solely those of the author(s) and are not endorsed by BMJ. BMJ disclaims all liability and responsibility arising from any reliance placed on the content. Where the content includes any translated material, BMJ does not warrant the accuracy and reliability of the translations (including but not limited to local regulations, clinical guidelines, terminology, drug names and drug dosages), and is not responsible for any error and/or omissions arising from translation and adaptation or otherwise.

Open access This is an open access article distributed in accordance with the Creative Commons Attribution Non Commercial (CC BY-NC 4.0) license, which permits others to distribute, remix, adapt, build upon this work non-commercially, and license their derivative works on different terms, provided the original work is properly cited, appropriate credit is given, any changes made indicated, and the use is non-commercial. See: http://creativecommons.org/licenses/by-nc/4.0/.

ORCID iDs

Scott C Adams http://orcid.org/0000-0002-7669-8754

Julia McMillan http://orcid.org/0000-0002-2245-4367

Kirsten Salline http://orcid.org/0000-0003-3996-5654

Jessica Lavery http://orcid.org/0000-0002-2746-5647

Chaya S Moskowitz http://orcid.org/0000-0002-2850-8450

Konstantina Matsoukas http://orcid.org/0000-0002-1005-9968

Maggie M Z Chen http://orcid.org/0000-0003-3106-5141

Daniel Santa Mina http://orcid.org/0000-0003-4361-1656

Jessica M Scott http://orcid.org/0000-0002-4845-5800

Lee W Jones http://orcid.org/0000-0002-3716-8793

\section{REFERENCES}

1 Pedersen BK, Saltin B. Exercise as medicine - evidence for prescribing exercise as therapy in 26 different chronic diseases. Scand J Med Sci Sports 2015;25 Suppl 3:1-72.

2 Mezzani A, Hamm LF, Jones AM, et al. Aerobic exercise intensity assessment and prescription in cardiac rehabilitation: a joint position statement of the European association for cardiovascular prevention and rehabilitation, the American association of cardiovascular and pulmonary rehabilitation and the Canadian association of cardiac rehabilitation. Eur J Prev Cardiol 2013;20:442-67.

3 Rochester CL, Vogiatzis I, Holland AE, et al. An official American thoracic Society/European respiratory Society policy statement: enhancing implementation, use, and delivery of pulmonary rehabilitation. Am J Respir Crit Care Med 2015;192:1373-86.

4 Sanft T, Denlinger CS, Armenian S. NCCN guidelines insights: survivorship, version 2.2019: Featured updates to the NCCN guidelines. J Natl Compr Canc Netw 2019;17:784-94.

5 Guyatt GH, Oxman AD, Vist GE, et al. Grade: an emerging consensus on rating quality of evidence and strength of recommendations. BMJ 2008;336:924-6.

6 Boutron I, Altman DG, Moher D, et al. Consort statement for randomized trials of nonpharmacologic treatments: a 2017 update and a consort extension for nonpharmacologic trial Abstracts. Ann Intern Med 2017;167:40-7.

7 Schulz KF, Altman DG, Moher D. Statement: updated guidelines for reporting parallel group randomized trials. Ann Intern Med 2010;2010:726-32.

8 Hoffmann TC, Glasziou PP, Boutron I, et al. Better reporting of interventions: template for intervention description and replication (TIDieR) checklist and guide. BMJ 2014;348:g1687.

9 Higgins JPT, Altman DG, Gøtzsche PC, et al. The Cochrane collaboration's tool for assessing risk of bias in randomised trials. BMJ 2011;343:d5928.

10 Jadad AR, Moore RA, Carroll D, et al. Assessing the quality of reports of randomized clinical trials: is blinding necessary? Control Clin Trials 1996;17:1-12. 
11 Jacquier I, Boutron I, Moher D, et al. The reporting of randomized clinical trials using a surgical intervention is in need of immediate improvement: a systematic review. Ann Surg 2006;244:677-83.

12 Chen W, Yu J, Zhang L, et al. Quality of reporting in randomized controlled trials of therapeutic cardiovascular medical devices. Surgery 2019;165:965-9.

13 Ritchie A, Seubert L, Clifford R, et al. Do randomised controlled trials relevant to pharmacy meet best practice standards for quality conduct and reporting? A systematic review. Int J Pharm Pract 2020;28:220-32.

14 Borror A, Zieff G, Battaglini C, et al. The effects of postprandial exercise on glucose control in individuals with type 2 diabetes: a systematic review. Sports Med 2018;48:1479-91.

15 Chan E, Giallauria F, Vigorito C, et al. Exercise training in heart failure patients with preserved ejection fraction: a systematic review and meta-analysis. Monaldi Arch Chest Dis 2016;86:759.

16 Grace A, Chan E, Giallauria F, et al. Clinical outcomes and glycaemic responses to different aerobic exercise training intensities in type II diabetes: a systematic review and metaanalysis. Cardiovasc Diabetol 2017:16:37.

17 Ostman C, Smart NA, Morcos D, et al. The effect of exercise training on clinical outcomes in patients with the metabolic syndrome: a systematic review and meta-analysis. Cardiovasc Diabetol 2017;16:110.

18 van Rosendal SP, Osborne MA, Fassett RG, et al. Guidelines for glycerol use in hyperhydration and rehydration associated with exercise. Sports Med 2010;40:113-29.

19 Bothwell LE, Greene JA, Podolsky SH, et al. Assessing the gold standard - lessons from the history of RCTs. N Engl J Med Overseas Ed 2016;374:2175-81.

20 Moher D, Liberati A, Tetzlaff J, et al. Preferred reporting items for systematic reviews and meta-analyses: the PRISMA statement. Ann Intern Med 2009;151:264-9.

21 Shea BJ, Grimshaw JM, Wells GA, et al. Development of AMSTAR: a measurement tool to assess the methodological quality of systematic reviews. BMC Med Res Methodol 2007;7:10.

22 Boutron I, Moher D, Altman DG, et al. Extending the CONSORT statement to randomized trials of nonpharmacologic treatment: explanation and elaboration. Ann Intern Med 2008;148:295-309.

23 Kunath F, Grobe HR, Rücker G, et al. Do journals publishing in the field of urology endorse reporting guidelines? A survey of author instructions. Urol Int 2012;88:54-9.

24 Samaan Z, Mbuagbaw L, Kosa D, et al. A systematic scoping review of adherence to reporting guidelines in health care literature. J Multidiscip Healthc 2013;6:169-88.

25 Mills E, Wu P, Gagnier J, et al. An analysis of general medical and specialist journals that endorse consort found that reporting was not enforced consistently. J Clin Epidemiol 2005;58:662-7.

26 American College of Sports Medicine. ACSM's guidelines for exercise testing and prescription: Wolters Kluwer. 11th ed, 2018.

27 Caspersen CJ, Powell KE, Christenson GM. Physical activity, exercise, and physical fitness: definitions and distinctions for health-related research. Public Health Rep 1985;100:126-31.

28 Shea BJ, Reeves BC, Wells G, et al. AMSTAR 2: a critical appraisal tool for systematic reviews that include randomised or nonrandomised studies of healthcare interventions, or both. BMJ 2017;358:j4008

29 Fleming PS, Koletsi D, Seehra J, et al. Systematic reviews published in higher impact clinical journals were of higher quality. $J$ Clin Epidemiol 2014;67:754-9.

30 Gluud LL, Sørensen TIA, Gøtzsche PC, et al. The Journal impact factor as a predictor of trial quality and outcomes: cohort study of hepatobiliary randomized clinical trials. Am J Gastroenterol 2005; 100:2431-5.

31 loannidis JPA, Evans SJW, Gøtzsche PC, et al. Better reporting of harms in randomized trials: an extension of the CONSORT statement. Ann Intern Med 2004;141:781-8.

32 Koo TK, Li MY. A guideline of selecting and reporting intraclass correlation coefficients for reliability research. J Chiropr Med 2016:15:155-63.

33 R Core Team. R: a language and environment for statistical computing. 467. Vienna, Austria, 2020.

34 Adamsen L, Quist M, Andersen C, et al. Effect of a multimodal high intensity exercise intervention in cancer patients undergoing chemotherapy: randomised controlled trial. BMJ 2009;339:b3410 .

35 Beckers PJ, Denollet J, Possemiers NM, et al. Combined endurance-resistance training vs. endurance training in patients with chronic heart failure: a prospective randomized study. Eur Heart J 2008;29:1858-66.

36 Beer M, Wagner D, Myers J, et al. Effects of exercise training on myocardial energy metabolism and ventricular function assessed by quantitative phosphorus-31 magnetic resonance spectroscopy and magnetic resonance imaging in dilated cardiomyopathy. J Am Coll Cardiol 2008;51:1883-91.

37 Belardinelli R, Georgiou D, Cianci G, et al. 10-Year exercise training in chronic heart failure: a randomized controlled trial. J Am Coll Cardiol 2012;60:1521-8.

38 Campbell KL, Foster-Schubert KE, Alfano CM, et al. Reducedcalorie dietary weight loss, exercise, and sex hormones in postmenopausal women: randomized controlled trial. $J$ Clin Oncol 2012:30:2314-26

39 Church TS, Blair SN, Cocreham S, et al. Effects of aerobic and resistance training on hemoglobin A1c levels in patients with type 2 diabetes: a randomized controlled trial. JAMA 2010;304:2253-62.

40 Courneya KS, Sellar CM, Stevinson C, et al. Randomized controlled trial of the effects of aerobic exercise on physical functioning and quality of life in lymphoma patients. J Clin Oncol 2009;27:4605-12.

41 Daumit GL, Dickerson FB, Wang N-Y, et al. A behavioral weight-loss intervention in persons with serious mental illness. N Engl J Med 2013;368:1594-602.

42 Dieli-Conwright CM, Courneya KS, Demark-Wahnefried W, et al. Effects of aerobic and resistance exercise on metabolic syndrome, sarcopenic obesity, and circulating biomarkers in overweight or obese survivors of breast cancer: a randomized controlled trial. JCO 2018;36:875-83.

43 Duijts SFA, van Beurden M, Oldenburg HSA, et al. Efficacy of cognitive behavioral therapy and physical exercise in alleviating treatment-induced menopausal symptoms in patients with breast cancer: results of a randomized, controlled, multicenter trial. J Clin Oncol 2012;30:4124-33.

44 Edelmann F, Gelbrich G, Düngen H-D, et al. Exercise training improves exercise capacity and diastolic function in patients with heart failure with preserved ejection fraction: results of the Ex-DHF (exercise training in diastolic heart failure) pilot study. J Am Coll Cardiol 2011;58:1780-91.

45 Ehlken N, Lichtblau M, Klose $\mathrm{H}$, et al. Exercise training improves peak oxygen consumption and haemodynamics in patients with severe pulmonary arterial hypertension and inoperable chronic thrombo-embolic pulmonary hypertension: a prospective, randomized, controlled trial. Eur Heart J 2016;37:35-44.

46 Fakhry F, Spronk S, van der Laan L, et al. Endovascular revascularization and supervised exercise for peripheral artery disease and intermittent claudication: a randomized clinical trial. JAMA 2015;314:1936-44.

47 Friedenreich CM, Neilson HK, O'Reilly R, et al. Effects of a high vs moderate volume of aerobic exercise on adiposity outcomes in postmenopausal women: a randomized clinical trial. JAMA Oncol 2015;1:766-76.

48 Friedenreich CM, Woolcott CG, McTiernan A, et al. Alberta physical activity and breast cancer prevention trial: sex hormone changes in a year-long exercise intervention among postmenopausal women. $J$ Clin Oncol 2010;28:1458-66.

49 Galvão DA, Spry N, Denham J, et al. A multicentre year-long randomised controlled trial of exercise training targeting physical functioning in men with prostate cancer previously treated with androgen suppression and radiation from TROG 03.04 radar. Eur Urol 2014;65:856-64.

50 Galvão DA, Taaffe DR, Spry N, et al. Combined resistance and aerobic exercise program reverses muscle loss in men undergoing androgen suppression therapy for prostate cancer without bone metastases: a randomized controlled trial. J Clin Oncol 2010;28:340-7.

51 Hallsworth K, Fattakhova G, Hollingsworth KG, et al. Resistance exercise reduces liver fat and its mediators in non-alcoholic fatty liver disease independent of weight loss. Gut 2011;60:1278-83.

52 Hollekim-Strand SM, Bjørgaas MR, Albrektsen G, et al. Highintensity interval exercise effectively improves cardiac function in patients with type 2 diabetes mellitus and diastolic dysfunction: a randomized controlled trial. J Am Coll Cardiol 2014:64:1758-60.

53 Irwin ML, Cartmel B, Gross CP, et al. Randomized exercise trial of aromatase inhibitor-induced arthralgia in breast cancer survivors. $J$ Clin Oncol 2015;33:1104-11

54 Johansen MY, MacDonald CS, Hansen KB, et al. Effect of an intensive lifestyle intervention on glycemic control in patients with type 2 diabetes: a randomized clinical trial. JAMA 2017;318:637-46.

55 Jones LW, Hornsby WE, Freedland SJ, et al. Effects of nonlinear aerobic training on erectile dysfunction and cardiovascular function following radical prostatectomy for clinically localized prostate cancer. Eur Urol 2014;65:852-5.

56 Kitzman DW, Brubaker P, Morgan T, et al. Effect of caloric restriction or aerobic exercise training on peak oxygen consumption and quality of life in obese older patients with heart failure with 
preserved ejection fraction: a randomized clinical trial. JAMA 2016;315:36-46.

57 Kitzman DW, Brubaker PH, Herrington DM, et al. Effect of endurance exercise training on endothelial function and arterial stiffness in older patients with heart failure and preserved ejection fraction: a randomized, controlled, single-blind trial. J Am Coll Cardiol 2013;62:584-92.

58 Ligibel JA, Campbell N, Partridge A, et al. Impact of a mixed strength and endurance exercise intervention on insulin levels in breast cancer survivors. J Clin Oncol 2008;26:907-12.

59 Maltais F, Bourbeau J, Shapiro S, Maltais F, et al. Effects of home-based pulmonary rehabilitation in patients with chronic obstructive pulmonary disease: a randomized trial. Ann Intern Med 2008;149:869-78.

60 McDermott MM, Ades P, Guralnik JM, et al. Treadmill exercise and resistance training in patients with peripheral arterial disease with and without intermittent claudication: a randomized controlled trial. JAMA 2009;301:165-74.

61 McDermott MM, Ferrucci L, Tian L, et al. Effect of granulocytemacrophage colony-stimulating factor with or without supervised exercise on walking performance in patients with peripheral artery disease: the PROPEL randomized clinical trial. JAMA 2017;318:2089-98.

62 McDermott MM, Spring B, Berger JS, et al. Effect of a homebased exercise intervention of wearable technology and telephone coaching on walking performance in peripheral artery disease: the honor randomized clinical trial. JAMA 2018;319:1665-76.

63 Messier SP, Mihalko SL, Legault C, et al. Effects of intensive diet and exercise on knee joint loads, inflammation, and clinical outcomes among overweight and obese adults with knee osteoarthritis: the idea randomized clinical trial. JAMA 2013;310:1263-73.

64 Monninkhof EM, Velthuis MJ, Peeters PHM, et al. Effect of exercise on postmenopausal sex hormone levels and role of body fat: a randomized controlled trial. J Clin Oncol 2009;27:4492-9.

65 Murphy TP, Cutlip DE, Regensteiner JG, et al. Supervised exercise, stent revascularization, or medical therapy for claudication due to aortoiliac peripheral artery disease: the clever study. J Am Coll Cardiol 2015;65:999-1009.

66 O'Connor CM, Whellan DJ, Lee KL, et al. Efficacy and safety of exercise training in patients with chronic heart failure: HF-ACTION randomized controlled trial. JAMA 2009;301:1439-50.

67 Pahor M, Guralnik JM, Ambrosius WT, et al. Effect of structured physical activity on prevention of major mobility disability in older adults: the life study randomized clinical trial. JAMA 2014;311:2387-96.

68 Patwala AY, Woods PR, Sharp L, et al. Maximizing patient benefit from cardiac resynchronization therapy with the addition of structured exercise training: a randomized controlled study. J Am Coll Cardiol 2009;53:2332-9.

69 Pitkälä KH, Pöysti MM, Laakkonen M-L, et al. Effects of the Finnish Alzheimer disease exercise trial (FINALEX): a randomized controlled trial. JAMA Intern Med 2013;173:894-901.

70 Ross R, Hudson R, Stotz PJ, et al. Effects of exercise amount and intensity on abdominal obesity and glucose tolerance in obese adults: a randomized trial. Ann Intern Med 2015;162:325-34.

71 Saberi S, Wheeler M, Bragg-Gresham J, et al. Effect of moderateintensity exercise training on peak oxygen consumption in patients with hypertrophic cardiomyopathy: a randomized clinical trial. JAMA 2017;317:1349-57.

72 Sandri M, Kozarez I, Adams V, et al. Age-Related effects of exercise training on diastolic function in heart failure with reduced ejection fraction: the Leipzig exercise intervention in chronic heart failure and aging (LEICA) diastolic dysfunction study. Eur Heart $J$ 2012;33:1758-68

73 Schmitz KH, Ahmed RL, Troxel A, et al. Weight lifting in women with breast-cancer-related lymphedema. N Engl J Med 2009;361:664-73.

74 Schmitz KH, Ahmed RL, Troxel AB, et al. Weight lifting for women at risk for breast Cancer-Related lymphedema. JAMA 2010;304:2699-705

75 Segal RJ, Reid RD, Courneya KS, et al. Randomized controlled trial of resistance or aerobic exercise in men receiving radiation therapy for prostate cancer. JCO 2009;27:344-51.

76 Taaffe DR, Newton RU, Spry N, et al. Effects of different exercise modalities on fatigue in prostate cancer patients undergoing androgen deprivation therapy: a year-long randomised controlled trial. Eur Urol 2017;72:293-9.

77 van Waart $\mathrm{H}$, Stuiver MM, van Harten WH, et al. Effect of lowintensity physical activity and moderate- to high-intensity physical exercise during adjuvant chemotherapy on physical fitness, fatigue, and chemotherapy completion rates: results of the PACES randomized clinical trial. J Clin Oncol 2015;33:1918-27.

78 Villareal DT, Aguirre L, Gurney AB, et al. Aerobic or resistance exercise, or both, in dieting obese older adults. $N$ Engl J Med 2017;376:1943-55

79 Villareal DT, Chode S, Parimi N, et al. Weight loss, exercise, or both and physical function in obese older adults. N Engl J Med 2011;364:1218-29.

80 Winter MM, van der Bom T, de Vries LCS, et al. Exercise training improves exercise capacity in adult patients with a systemic right ventricle: a randomized clinical trial. Eur Heart J 2012;33:1378-85.

81 Zhang $\mathrm{H}-\mathrm{J}, \mathrm{He} J$, Pan $\mathrm{L}-\mathrm{L}$, et al. Effects of moderate and vigorous exercise on nonalcoholic fatty liver disease: a randomized clinical trial. JAMA Intern Med 2016;176:1074-82.

82 Ahmed S, Rienstra M, Crijns HJGM, et al. Continuous vs episodic prophylactic treatment with amiodarone for the prevention of atrial fibrillation: a randomized trial. JAMA 2008;300:1784-92.

83 Caminiti G, Volterrani M, lellamo F, et al. Effect of long-acting testosterone treatment on functional exercise capacity, skeletal muscle performance, insulin resistance, and baroreflex sensitivity in elderly patients with chronic heart failure a double-blind, placebo-controlled, randomized study. J Am Coll Cardiol 2009;54:919-27.

84 Cortelazzo S, Tarella C, Gianni AM, et al. Randomized trial comparing $\mathrm{R}-\mathrm{CHOP}$ versus high-dose sequential chemotherapy in high-risk patients with diffuse large B-cell lymphomas. J Clin Oncol 2016;34:4015-22.

85 Cummings JL, Lyketsos CG, Peskind ER, et al. Effect of Dextromethorphan-Quinidine on agitation in patients with Alzheimer disease dementia: a randomized clinical trial. JAMA 2015;314:1242-54

86 Cusi K, Orsak B, Bril F, et al. Long-Term pioglitazone treatment for patients with nonalcoholic steatohepatitis and prediabetes or type 2 diabetes mellitus: a randomized trial. Ann Intern Med 2016;165:305-15.

87 Devereux G, Cotton S, Fielding S, et al. Effect of theophylline as adjunct to inhaled corticosteroids on exacerbations in patients with COPD: a randomized clinical trial. JAMA 2018;320:1548-59.

88 Ellis MJ, Suman VJ, Hoog J, et al. Randomized phase II neoadjuvant comparison between letrozole, anastrozole, and exemestane for postmenopausal women with estrogen receptorrich stage 2 to 3 breast cancer: clinical and biomarker outcomes and predictive value of the baseline PAM50-based intrinsic subtype-ACOSOG Z1031. J Clin Oncol 2011;29:2342-9.

89 Ford I, Scott NW, Herd V, et al. A randomized controlled trial of platelet activity before and after cessation of clopidogrel therapy in patients with stable cardiovascular disease. J Am Coll Cardiol 2014;63:233-9.

90 Frustaci A, Russo MA, Chimenti C. Randomized study on the efficacy of immunosuppressive therapy in patients with virusnegative inflammatory cardiomyopathy: the TIMIC study. Eur Heart J 2009;30:1995-2002.

91 Gheorghiade M, Blair JEA, Filippatos GS, et al. Hemodynamic, echocardiographic, and neurohormonal effects of istaroxime, a novel intravenous inotropic and lusitropic agent: a randomized controlled trial in patients hospitalized with heart failure. J Am Coll Cardiol 2008:51:2276-85.

92 Gheorghiade M, Böhm M, Greene SJ, et al. Effect of aliskiren on postdischarge mortality and heart failure readmissions among patients hospitalized for heart failure: the astronaut randomized trial. JAMA 2013;309:1125-35.

93 Goebel A, Bisla J, Carganillo R, et al. Low-Dose intravenous immunoglobulin treatment for long-standing complex regional pain syndrome: a randomized trial. Ann Intern Med 2017;167:476-83.

94 Greenspan SL, Brufsky A, Lembersky BC, et al. Risedronate prevents bone loss in breast cancer survivors: a 2-year, randomized, double-blind, placebo-controlled clinical trial. J Clin Oncol 2008;26:2644-52.

95 Grudell ABM, Sweetser S, Camilleri M, et al. A controlled pharmacogenetic trial of sibutramine on weight loss and body composition in obese or overweight adults. Gastroenterology 2008;135:1142-54.

96 Hamshere S, Arnous S, Choudhury T, et al. Randomized tria of combination cytokine and adult autologous bone marrow progenitor cell administration in patients with non-ischaemic dilated cardiomyopathy: the REGENERATE-DCM clinical trial. Eur Heart $J$ 2015;36:3061-9.

97 Han $Y$, Zhu G, Han L, et al. Short-term rosuvastatin therapy for prevention of contrast-induced acute kidney injury in patients with diabetes and chronic kidney disease. J Am Coll Cardiol 2014;63:62-70. 
98 Harman SM, Black DM, Naftolin F, et al. Arterial imaging outcomes and cardiovascular risk factors in recently menopausal women: a randomized trial. Ann Intern Med 2014;161:249-60.

99 Hoendermis ES, Liu LCY, Hummel YM, et al. Effects of sildenafil on invasive haemodynamics and exercise capacity in heart failure patients with preserved ejection fraction and pulmonary hypertension: a randomized controlled trial. Eur Heart J 2015;36:2565-73.

100 Hurvitz SA, Dirix L, Kocsis J, et al. Phase II randomized study of trastuzumab emtansine versus trastuzumab plus docetaxel in patients with human epidermal growth factor receptor 2-Positive metastatic breast cancer. JCO 2013;31:1157-63.

101 Irani J, Celhay O, Hubert J, et al. Continuous versus six months a year maximal androgen blockade in the management of prostate cancer: a randomised study. Eur Urol 2008;54:382-91.

102 Johnston SRD, Hegg R, Im S-A, et al. Phase III, randomized study of dual human epidermal growth factor receptor 2 (HER2) blockade with lapatinib plus trastuzumab in combination with an aromatase inhibitor in postmenopausal women with HER2-positive, hormone receptor-positive metastatic breast cancer: alternative. J Clin Oncol 2018;36:741-8.

103 Kim J-M, Stewart R, Lee Y-S, et al. Effect of escitalopram vs placebo treatment for depression on long-term cardiac outcomes in patients with acute coronary syndrome: a randomized clinical trial. JAMA 2018;320:350-8.

104 Klotz LH, McNeill IY, Kebabdjian M, et al. A phase 3, double-blind, randomised, parallel-group, placebo-controlled study of oral Weekly alendronate for the prevention of androgen deprivation bone loss in nonmetastatic prostate cancer: the cancer and osteoporosis research with alendronate and leuprolide (coral) study. Eur Urol 2013:63:927-35.

105 Kosmala W, Holland DJ, Rojek A, et al. Effect of If-channel inhibition on hemodynamic status and exercise tolerance in heart failure with preserved ejection fraction: a randomized trial. J Am Coll Cardiol 2013;62:1330-8.

106 Kosmala W, Rojek A, Przewlocka-Kosmala M, et al. Effect of Aldosterone Antagonism on Exercise Tolerance in Heart Failure With Preserved Ejection Fraction. J Am Coll Cardiol 2016;68:1823-34.

107 Krankenberg H, Tübler T, Ingwersen $\mathrm{M}$, et al. Drug-Coated balloon versus standard balloon for superficial femoral artery in-stent restenosis: the randomized femoral artery in-stent restenosis (fair) trial. Circulation 2015;132:2230-6.

108 Lapperre TS, Snoeck-Stroband JB, Gosman MME, et al. Effect of fluticasone with and without salmeterol on pulmonary outcomes in chronic obstructive pulmonary disease: a randomized trial. Ann Intern Med 2009;151:517-27.

109 Loprinzi CL, Qin R, Balcueva EP, et al. Phase III, randomized, double-blind, placebo-controlled evaluation of pregabalin for alleviating hot flashes, N07C1. J Clin Oncol 2010;28:641-7.

110 McKay RR, Zurita AJ, Werner L, et al. A randomized phase II trial of short-course androgen deprivation therapy with or without bevacizumab for patients with recurrent prostate cancer after definitive local therapy. J Clin Oncol 2016;34:1913-20.

111 Nissen SE, Nicholls SJ, Wolski K, et al. Comparison of pioglitazone vs glimepiride on progression of coronary atherosclerosis in patients with type 2 diabetes: the periscope randomized controlled trial. JAMA 2008;299:1561-73.

112 Poole J, Mavromatis K, Binongo JN, et al. Effect of progenitor cell mobilization with granulocyte-macrophage colony-stimulating factor in patients with peripheral artery disease: a randomized clinical trial. JAMA 2013;310:2631-9.

113 Pradhan AD, Everett BM, Cook NR, et al. Effects of initiating insulin and metformin on glycemic control and inflammatory biomarkers among patients with type 2 diabetes: the Lancet randomized trial. JAMA 2009;302:1186-94.

114 Ratziu V, Giral P, Jacqueminet S, et al. Rosiglitazone for nonalcoholic steatohepatitis: one-year results of the randomized placebo-controlled fatty liver improvement with rosiglitazone therapy (FLIRT) trial. Gastroenterology 2008;135:100-10.

115 Rimawi M, Ferrero J-M, de la Haba-Rodriguez J, et al. FirstLine trastuzumab plus an aromatase inhibitor, with or without pertuzumab, in human epidermal growth factor receptor 2-positive and hormone receptor-positive metastatic or locally advanced breast cancer (PERTAIN): a randomized, open-label phase II trial. $J$ Clin Oncol 2018;36:2826-35.

116 Rosenheck RA, Krystal JH, Lew R, et al. Long-acting risperidone and oral antipsychotics in unstable schizophrenia. N Engl J Med 2011:364:842-51

117 Schmid P, Pinder SE, Wheatley D, et al. Phase II randomized preoperative Window-of-Opportunity study of the PI3K inhibitor Pictilisib plus anastrozole compared with anastrozole alone in patients with estrogen receptor-positive breast cancer. $J$ Clin Oncol 2016;34:1987-94.

118 Smith SR, Weissman NJ, Anderson CM, et al. Multicenter, placebocontrolled trial of lorcaserin for weight management. N Engl J Med 2010;363:245-56.

119 Soiffer RJ, Kim HT, McGuirk J, et al. Prospective, randomized, double-blind, phase III clinical trial of Anti-T-Lymphocyte globulin to assess impact on chronic graft-versus-host disease-free survival in patients undergoing HLA-matched unrelated myeloablative hematopoietic cell transplantation. J Clin Oncol 2017;35:4003-11.

120 Spitzer M, Basaria S, Travison TG, et al. Effect of testosterone replacement on response to sildenafil citrate in men with erectile dysfunction: a parallel, randomized trial. Ann Intern Med 2012;157:681-91.

121 Taplin M-E, Montgomery B, Logothetis CJ, et al. Intense androgendeprivation therapy with abiraterone acetate plus leuprolide acetate in patients with localized high-risk prostate cancer: results of a randomized phase II neoadjuvant study. J Clin Oncol 2014;32:3705-15.

122 Tsujita $\mathrm{K}$, Sugiyama S, Sumida $\mathrm{H}$, et al. Impact of dual lipid-lowering strategy with ezetimibe and atorvastatin on coronary plaque regression in patients with percutaneous coronary intervention: the multicenter randomized controlled PRECISE-IVUS trial. J Am Coll Cardiol 2015;66:495-507.

123 Ulrich S, Keusch S, Hildenbrand FF, et al. Effect of nocturnal oxygen and acetazolamide on exercise performance in patients with pre-capillary pulmonary hypertension and sleep-disturbed breathing: randomized, double-blind, cross-over trial. Eur Heart $J$ 2015;36:615-23.

124 Urruticoechea A, Rizwanullah M, Im S-A, et al. Randomized phase III trial of trastuzumab plus capecitabine with or without pertuzumab in patients with human epidermal growth factor receptor 2-positive metastatic breast cancer who experienced disease progression during or after trastuzumab-based therapy. J Clin Oncol 2017;35:3030-8.

125 van der Bom T, Winter MM, Bouma BJ, et al. Effect of valsartan on systemic right ventricular function: a double-blind, randomized, placebo-controlled pilot trial. Circulation 2013;127:322-30.

126 Wapnir IL, Price KN, Anderson SJ, et al. Efficacy of chemotherapy for ER-negative and ER-positive isolated locoregional recurrence of breast cancer: final analysis of the CALOR trial. $J$ Clin Oncol 2018;36:1073-9.

127 Wysham C, Bhargava A, Chaykin L, et al. Effect of insulin degludec vs insulin glargine u100 on hypoglycemia in patients with type 2 diabetes: the switch 2 randomized clinical trial. JAMA 2017;318:45-56.

128 Yardley DA, Ismail-Khan RR, Melichar B, et al. Randomized phase II, double-blind, placebo-controlled study of exemestane with or without entinostat in postmenopausal women with locally recurrent or metastatic estrogen receptor-positive breast cancer progressing on treatment with a nonsteroidal aromatase inhibitor. $J$ Clin Oncol 2013:31:2128-35.

129 Yoshimura K, Minami T, Nozawa M, et al. A phase 2 randomized controlled trial of personalized peptide vaccine immunotherapy with low-dose dexamethasone versus dexamethasone alone in Chemotherapy-naive castration-resistant prostate cancer. Eur Urol 2016;70:35-41.

130 Smart NA, Waldron $\mathrm{M}$, Ismail $\mathrm{H}$, et al. Validation of a new tool for the assessment of study quality and reporting in exercise training studies: TESTEX. Int J Evid Based Healthc 2015;13:9-18.

131 Maher CG, Moseley AM, Sherrington C, et al. A description of the trials, reviews, and practice guidelines indexed in the PEDro database. Phys Ther 2008;88:1068-77.

132 Verhagen AP, de Vet HCW, de Bie RA, et al. The Delphi list. J Clin Epidemiol 1998;51:1235-41.

133 McNeely ML, Campbell KL, Rowe BH, et al. Effects of exercise on breast cancer patients and survivors: a systematic review and meta-analysis. CMAJ 2006;175:34-41.

134 Larun L, Brurberg KG, Odgaard-Jensen J, et al. Exercise therapy for chronic fatigue syndrome. Cochrane Database Syst Rev 2019;10:CD003200.

135 Pilutti LA, Platta ME, Motl RW, et al. The safety of exercise training in multiple sclerosis: a systematic review. J Neurol Sci 2014;343:3-7.

136 Péron J, Maillet D, Gan HK, et al. Adherence to consort adverse event reporting guidelines in randomized clinical trials evaluating systemic cancer therapy: a systematic review. J Clin Oncol 2013:31:3957-63

137 Tew GA, Brabyn S, Cook L, et al. The completeness of intervention descriptions in randomised trials of supervised exercise training in peripheral arterial disease. PLoS One 2016;11:e0150869. 
138 Meneses-Echavez JF, Rodriguez-Prieto I, Elkins M, et al. Analysis of reporting completeness in exercise cancer trials: a systematic review. BMC Med Res Methodol 2019;19:220.

139 Hacke C, Nunan D, Weisser B. Do exercise trials for hypertension adequately report interventions? A reporting quality study. Int $J$ Sports Med 2018;39:902-8.

140 McEwen D, O'Neil J, Miron-Celis M, et al. Content reporting in poststroke therapeutic circuit-class exercise programs in randomized control trials. Top Stroke Rehabil 2019;26:281-7.

141 Scott JM, Zabor EC, Schwitzer E, et al. Efficacy of exercise therapy on cardiorespiratory fitness in patients with cancer: a systematic review and meta-analysis. J Clin Oncol 2018;36:2297-305

142 Péron J, Pond GR, Gan HK, et al. Quality of reporting of modern randomized controlled trials in medical oncology: a systematic review. J Natl Cancer Inst 2012;104:982-9.

143 Begg C, Cho M, Eastwood S, et al. Improving the quality of reporting of randomized controlled trials. The CONSORT statement. JAMA 1996;276:637-9.
144 Han C, Kwak K-phil, Marks DM, et al. The impact of the CONSORT statement on reporting of randomized clinical trials in psychiatry. Contemp Clin Trials 2009;30:116-22.

145 Moher D, Jones A, Lepage L, et al. Use of the CONSORT statement and quality of reports of randomized trials: a comparative beforeand-after evaluation. JAMA 2001;285:1992-5.

146 Plint AC, Moher D, Morrison A, et al. Does the CONSORT checklist improve the quality of reports of randomised controlled trials? A systematic review. Med J Aust 2006;185:263-7.

147 Slade SC, Dionne CE, Underwood M, et al. Consensus on exercise reporting template (CERT): explanation and elaboration statement. Br J Sports Med 2016;50:1428-37.

148 MacPherson H, Altman DG, Hammerschlag R, et al. Revised standards for reporting interventions in clinical trials of acupuncture (stricta): extending the CONSORT statement. The Journal of Alternative and Complementary Medicine 2010;16:ST-1-ST-14.

149 Calvert M, Blazeby J, Altman DG, et al. Reporting of patientreported outcomes in randomized trials: the CONSORT pro extension. JAMA 2013;309:814-22. 